\title{
A start-up of psychrophilic anaerobic sequence batch reactor digesting a $35 \%$ total solids feed of dairy manure and wheat straw
}

\author{
Noori M. Cata Saady and Daniel I. Massé*
}

\begin{abstract}
Zero liquid discharge is currently an objective in livestock manure management to minimize water pollution. This paper reports the start-up phase of a novel psychrophilic $\left(20^{\circ} \mathrm{C}\right)$ dry anaerobic digestion of dairy manure with bedding fed at $35 \%$ total solids and an organic loading rate of $3.0 \mathrm{~g}$ total chemical oxygen demand $\mathrm{kg}^{-1}$ inoculum day ${ }^{-1}$ in anaerobic sequence batch reactors. The specific methane $\left(\mathrm{CH}_{4}\right)$ yield ranged from $165.4 \pm 9.8$ to $213.9 \pm 13.6 \mathrm{NL}$ $\mathrm{CH}_{4} \mathrm{~kg}^{-1}$ volatile solids (VS) with an overall average of $188 \pm 17 \mathrm{NL} \mathrm{CH}_{4} \mathrm{~kg}^{-1}$ VS during 11 successive start-up cycles (231 days) and a maximum $\mathrm{CH}_{4}$ production rate of $10.2 \pm 0.6 \mathrm{NL} \mathrm{CH}_{4} \mathrm{~kg}^{-1} \mathrm{VS}$ day ${ }^{-1}$. The inoculum-to-substrate (VSbased) ratio ranged from 4.06 to 4.47 . Although methanogenesis proceeded fairly well the hydrolysis seemed to be the rate limiting step. It is possible start up psychrophilic dry anaerobic digestion of cow feces and wheat straw at feed TS of $35 \%$ within 7-10 successive cycles (147-210 days).
\end{abstract}

Keywords: Dry anaerobic digestion, Cow manure, Methane, Psychrophilic, Wheat straw, Start-up

\section{Introduction}

Environmental regulations aim to decrease the adverse impact of agricultural activities on the natural resources and environment. In this context, livestock industry produces large amount of manure that needs to be treated, stabilized, and converted to fertilizers; one opportunity to extract energy from livestock manure is the use of anaerobic digestion. In Canada and USA, cattle generate about 75 and $86 \%$ of the manure produced by livestock, respectively (Hofmann and Beaulieu 2006; Wen et al. 2004). Although fresh cow feces has a total solids (TS) content of about $12-14 \%$, the addition of bedding materials such as straw increases the total solids to more than $25 \%$ (El-Mashad et al. 2004). Conventional wet anaerobic digestion (WAD) is currently used to stabilize livestock manure, extract renewable energy, reduce its environmental impact, and convert it to fertilizers. However, WAD requires large reactors volume because influent has low total solids content $(<10 \%)$ (El-Mashad et al. 2004).

*Correspondence: daniel.masse@agr.gc.ca

Dairy and Swine Research and Development Centre,

Agriculture and Agri-Food Canada, Sherbrooke, QC J1M 0C8, Canada
Recently, dry anaerobic digestion (DAD) has gained more interest. The advantages of DAD have been demonstrated at mesophilic and thermophilic conditions for the organic fraction of municipal solid wastes (15\% TS) (Challen Urbanic et al. 2011; Li et al. 2011b; Ramasamy and Abbasi 2000) and for agricultural wastes and livestock manure (15-20 \% TS) (Ahn et al. 2010; Kusch et al. 2008; Di Maria et al. 2012). However, in cold-climate regions psychrophilic operation is desired. Obviously, heating the bioreactor to maintain mesophilic and thermophilic conditions is an energy drain. Kashyap et al. (2003) indicated that developing a psychrophilic anaerobic digestion process to convert cattle dung into biogas and meet the energy needs at cold-climate regions is still a technological challenge; since then on-farm psychrophilic WAD has been developed and deployed (Massé et al. 1996, 1997, 2007, 2010). Presently, developing and optimizing a psychrophilic dry anaerobic digestion process is of outmost importance and could fill a gap in the anaerobic digestion market.

Psychrophilic conditions decrease the rates of chemical and biological reactions compared to mesophilic and thermophilic operations. According to microbial

\section{Springer}


thermodynamic, a drop in temperature increases the energy required to enable the endothermic reactions of propionate and butyrate conversion to acetate. Similarly, temperature drop decreases the energy released from spontaneous exothermic reactions except for hydrogenotrophic microorganisms (Lettinga et al. 2001). The low rate of specific growth at psychrophilic condition restricts the lower threshold limit of the microorganisms' retention time to prevent biomass washout in continuous systems and to achieve reasonable degree of treatment in batch systems. Generally, the start-up of psychrophilic anaerobic digestion requires long time to enable retention of sufficient slow growing microbial biomass (Dhaked et al. 2010).

Recently, a psychrophilic $\left(20^{\circ} \mathrm{C}\right)$ dry anaerobic digestion (PDAD) of cow feces and wheat straw in sequential batch reactor (SBR), has been developed at Agriculture and Agri-Food, Dairy and swine Research and Development Centre (DSRDC) in Sherbrooke, QC, Canada to stabilize cow manure and convert it to biofuel (Massé and Saady 2015a, b, c; Saady and Massé 2015).

Massé and Saady (2015b) reported long term operation (252 days) of PDAD-SBR for digesting cow feces (TS 13-16 \%) with an average specific methane yield (SMY) of $222 \pm 27.2 \mathrm{NL} \mathrm{CH}_{4} \mathrm{~kg}^{-1}$ VS fed. Moreover, they demonstrated successful operation at TS of $27 \%$ and organic loading rate (OLR) of $3 \mathrm{~g}$ total chemical oxygen demand (TCOD) $\mathrm{kg}^{-1}$ inoculum day ${ }^{-1}$ for 273 days with an average SMY of $182.9 \pm 16.9 \mathrm{NL} \mathrm{CH}_{4} \mathrm{~kg}^{-1} \mathrm{VS}$ fed (Massé and Saady 2015c). They feasibility of PDAD-SBR of cow feces and wheat straw (27\% TS in feed) has been demonstrated at OLR of 4.0, 5.0, and $6.0 \mathrm{~g}_{\text {TCOD kg }}^{-1}$ inoculum day ${ }^{-1}$ in long term study (315 days) with SMYs of $187.3 \pm 18.1$, $163.6 \pm 39.5,150.8 \pm 32.9 \mathrm{NL} \mathrm{CH}_{4} \mathrm{~kg}^{-1}$ VS fed, respectively (Saady and Massé 2015). The OLR of cow feces and wheat straw (27\% TS in feed) fed to PDAD-SBR has been increased to 7.0 and $8.0 \mathrm{~g}^{\mathrm{TCOD} \mathrm{kg}}{ }^{-1}$ inoculum day ${ }^{-1}$ in long term study (84 days) and SMYs of $147.1 \pm 17.2$, $143.2 \pm 11.7 \mathrm{NL} \mathrm{CH}_{4} \mathrm{~kg}^{-1}$ VS fed, respectively, have been reported (Massé and Saady 2015a).

Increasing the total solids content of the substrate fed to a DAD bioreactor is a basic engineering design objective to decrease the bioreactor volume (Luning et al. 2003), reduce its construction costs, and increase the specific energy output per reactor's unit volume. However, Motte et al. (2013) concluded that mesophilic acidogenesis of wheat straw decreased with the increase in its TS from 10 to $33 \%$ but with no changes in the metabolic pathway until a clear limit at $28 \%$ TS.

The principal objective of this study was to assess the feasibility of starting-up a psychrophilic $\left(20{ }^{\circ} \mathrm{C}\right)$ dry anaerobic digestion of the dairy cow feces and wheat straw at $35 \%$ TS in feed in terms of specific methane yield, volatile solids removal, process stability and startup duration.

\section{Materials and methods}

\section{Experimental setup}

The experiments assessed the start-up strategy and duration of cow feces and wheat straw psychrophilic anaerobic digestion at feed total solids of $35 \%$ and an OLR of $3.0 \mathrm{~g}^{\mathrm{T} C O D ~ ~ k^{-1}}$ inoculum day ${ }^{-1}$. The operation comprised of 231 days involving eleven successive cycles. The treatment cycle length (TCL) was 21 days. The cycle includes the following steps: day 1: loading the reactor with inoculum, feeding the substrate, and mixing the inoculum and substrate; days 1-21: reaction; and day 21: unloading the digestate and starting the next cycle.

At the beginning of each cycle, the contents of the triplicate reactors were mixed and homogenized, then $6 \mathrm{~kg}$ of the mixture was used as an inoculum in each of the reactors, then each reactor received the amount of cow feces and wheat straw according to the OLR and TS desired, then the content of the bioreactor was mixed manually for $5 \mathrm{~min}$ and a representative sample $(50 \mathrm{~g})$ has been taken. Thereafter the reactor has been flushed with nitrogen to maintain anaerobic digestion. The mass of inoculum, feces, and/or straw fed to each bioreactor at the beginning of the successive cycles, the VS-based inoculum-to-substrate ratio (ISR) and the OLR are given in Table 1. All the feeding calculations have been based on target OLR as well as the masses of inoculum and the composition of cow feces and wheat straw. The digestion cycle was conducted in a static mode with no leachate recirculation. Physico-chemical characteristics of the inoculum and substrates (manure and straw) before feeding bioreactors were analyzed and are given in Table 2 .

\section{Bioreactor}

A triplicate of $40-\mathrm{L}$ cylindrical $(0.312 \mathrm{~m}$ in diameter $\times 0.520 \mathrm{~m}$ in height) plastic barrels bioreactors were set-up and operated as a SBR at a TCL of 21 days in a temperature controlled room $\left(20{ }^{\circ} \mathrm{C}\right)$. The reactors (Fig. 1) were fitted with two gas lines; one to purge the headspace with nitrogen gas immediately after feeding/ loading the substrate to expel $\mathrm{O}_{2}$ and initiate an anaerobic environment inside reactors; and the second to release and quantify the biogas produced. The barrel was kept upside down after it has been filled so that the lixiviate works as a water seal around the barrel's lid to ensure gas tightness.

\section{Inoculum and substrate}

The initial inoculum was obtained from a laboratory scale $(40 \mathrm{~L})$ psychrophilic $\left(20^{\circ} \mathrm{C}\right)$ anaerobic sequence batch reactor fed with fresh dairy manure and wheat 
Table 1 Organic loading rate and total solids of the feed

\begin{tabular}{|c|c|c|c|c|c|c|c|}
\hline \multirow[t]{2}{*}{ Cycle } & \multirow[t]{2}{*}{ Feces $(\mathbf{k g})$} & \multirow[t]{2}{*}{ Straw (kg) } & \multirow{2}{*}{$\begin{array}{l}\text { ISR } \\
\text { (VS-based ratio) }\end{array}$} & \multicolumn{4}{|c|}{ Organic loading Organic loading rate } \\
\hline & & & & TCOD fed (g) & VS fed (g) & $\begin{array}{l}\text { g TCOD substrate } \mathrm{kg}^{-1} \\
\text { inoculum day }\end{array}$ & $\begin{array}{l}\text { g VS substrate } \mathbf{k g}^{-1} \\
\text { inoculum day }\end{array}$ \\
\hline 1 & 0.70 & 0.30 & 4.47 & 378 & 334.8 & 3.0 & 2.66 \\
\hline 2 & 0.635 & 0.259 & 4.06 & 378 & 295.7 & 3.0 & 2.35 \\
\hline 3 & 0.545 & 0.252 & 4.30 & 378 & 279.1 & 3.0 & 2.22 \\
\hline 4 & 0.567 & 0.259 & 4.18 & 378 & 287.1 & 3.0 & 2.28 \\
\hline 5 & 0.567 & 0.259 & 4.18 & 378 & 284.2 & 3.0 & 2.26 \\
\hline 6 & 0.567 & 0.259 & 4.18 & 378 & 284.2 & 3.0 & 2.26 \\
\hline 7 & 0.606 & 0.247 & 4.32 & 378 & 278.4 & 3.0 & 2.28 \\
\hline 8 & 0.606 & 0.247 & 4.32 & 378 & 277.8 & 3.0 & 2.20 \\
\hline 9 & 0.606 & 0.247 & 4.32 & 378 & 277.8 & 3.0 & 2.20 \\
\hline 10 & 0.634 & 0.217 & 4.36 & 378 & 275.1 & 3.0 & 2.18 \\
\hline 11 & 0.634 & 0.217 & 4.36 & 378 & 275.1 & 3.0 & 2.18 \\
\hline
\end{tabular}

In all cycles the reactors have been inoculated with $6 \mathrm{~kg}$ of culture which has been transferred from the previous cycle. The feed TS has been kept at $35 \%$ in all cycles

straw (27 \% TS). Fresh feces from dairy cows was collected at the experimental farm of the DSRDC. Feces was collected on wood boards, to avoid dilution with urine, transferred into a plastic drum, stored at $4{ }^{\circ} \mathrm{C}$, before being fed to the reactors. Wheat straw was harvested at the DSRDC's experimental farm during fall 2011 and fall 2012 and chopped $(3 \mathrm{~mm}$ ) using a laboratory mill (Thomas Wiley Laboratory Mill Model 4, Arthur $\mathrm{H}$. Thomas Company, Philadelphia, PA, USA). Wheat straw and cow feces were mixed manually to obtain the desired substrate TS content (35\%) while maintaining the design OLR of $3.0 \mathrm{~g} \mathrm{TCOD} \mathrm{kg}^{-1}$ inoculum day ${ }^{-1}$.

\section{Organic loading rate}

The OLR has been calculated based on the masses of VS and TCOD of the substrate fed (Table 2). OLR was expressed in $\mathrm{g}$ of TCOD fed per $\mathrm{kg}$ of inoculum per day, and $\mathrm{g}$ of total VS fed per $\mathrm{kg}$ inoculum per day. The OLR expression based on mass of inoculum is more suitable for solid substrate in dry anaerobic digestion since measuring the volume is difficult because it is a function of the density or the degree of compaction and water content. The inoculum to substrate ratio (ISR; based on mass of VS) ranged between 4.06 and 4.47 . The percentage of substrate-to-inoculum (wet mass-based) ranged between 13.3 and $17.8 \%$.

\section{Sampling}

The inoculum-substrate mixture (ISM) was sampled on day (0) immediately after feeding. Samples were also taken on day 7 by opening the reactor, mixing its content manually for 5 min to ensure that the sample is representative of the reactor content. The reactor content was also sampled at the end of the treatment cycle (on day 21); this sample represented the digestate (effluent) of which $6 \mathrm{~kg}$ were used as inoculum in the next cycle. The gas samples were taken with a $10 \mathrm{~mL}$ plastic syringe through a gas sampling port sealed with septa and installed on the gas line mid-way between the barrel and the wet tip gas meter.

\section{Biogas measurement}

Biogas volume produced was measured daily using calibrated wet tip gas meters while the biogas components $\left(\mathrm{CH}_{4}, \mathrm{CO}_{2}\right.$ and $\left.\mathrm{H}_{2} \mathrm{~S}\right)$ were determined weekly using a Hach Carle 400 AGC gas chromatograph (Model 04131C, Chandler Engineering, Houston, TX, USA) configured for the application 131-C. The GC setup, protocol and calibration, detection levels, and relevant details were reported elsewhere. Methane $\left(\mathrm{CH}_{4}\right)$ production is reported in normalized litres $\left(\mathrm{NL} \mathrm{CH}_{4}\right)$, i.e., the $\mathrm{CH}_{4}$ volume produced was corrected to standard temperature and pressure (STP) $\left(273^{\circ} \mathrm{K} ; 1 \mathrm{~atm}\right.$.).

\section{Analytical methods}

Samples were collected from each bioreactor and analyzed weekly for volatile fatty acids (VFAs), TS, VS, and $\mathrm{pH}$. The TCOD was determined before and after each treatment cycle. TCOD, TS, VS, alkalinity and $\mathrm{pH}$ were determined using standard methods (APHA 1992). Alkalinity: method number $2320 \mathrm{~B}$ used potentiometric titration to preselected $\mathrm{pH} 4.38$, total solids: method number 2540B, Volatile solids method number: 2540E. VFA: method number 5560D.

The concentrations of individual VFAs including acetic, propionic, butyric, isobutyric, butyric, valeric and isovaleric acids have been measured using Perkin Elmer gas chromatograph (GC) model 8310 (Perkin Elmer, Waltham, Mass.) equipped with an autosampler 
Table 2 Physicochemical characteristics of the inoculum, cow feces and inoculum-substrate mixture at beginning of digestion cycle

\begin{tabular}{|c|c|c|c|c|c|c|c|c|c|}
\hline Cycle & Type & $\begin{array}{l}\text { Acetate } \\
\left(\mathrm{g} \mathrm{kg}^{-1}\right)\end{array}$ & $\begin{array}{l}\text { Propionate } \\
\left(\mathrm{g} \mathrm{kg}^{-1}\right)\end{array}$ & $\begin{array}{l}\text { Butyrate } \\
\left(\mathrm{g} \mathrm{kg}^{-1}\right)\end{array}$ & $\mathrm{pH}$ & $\begin{array}{l}\text { Alkalinity } \\
\left(\mathrm{g} \mathrm{kg}^{-1} \text { as }\right. \\
\left.\mathrm{CaCO}_{3}\right)\end{array}$ & $\begin{array}{l}\text { TCOD } \\
\left(\mathrm{g} \mathrm{kg}^{-1}\right)\end{array}$ & TS (\%) & VS (\%) \\
\hline \multirow[t]{3}{*}{1} & Inoculum & $0.77 \pm 0.47$ & $0.24 \pm 0.21$ & $0.28 \pm 0.08$ & $7.3 \pm 0.0$ & $11.5 \pm 0.55$ & & $11.0 \pm 0.6$ & $9.3 \pm 0.5$ \\
\hline & Feces & 4.5 & 1.1 & 0.93 & 5.89 & & 148.1 & 13.29 & 11.9 \\
\hline & ISM & $1.1 \pm 0.02$ & $0.25 \pm 0.02$ & $0.29 \pm 0.02$ & $7.1 \pm 0.0$ & & & $14.1 \pm 0.4$ & $12.0 \pm 0.6$ \\
\hline \multirow[t]{3}{*}{2} & Inoculum & $0.84 \pm 0.50$ & $0.32 \pm 0.22$ & $0.26 \pm 0.07$ & $7.4 \pm 0.1$ & $11.8 \pm 0.65$ & & $12.3 \pm 0.4$ & $10.6 \pm 0.4$ \\
\hline & Feces & 3.4 & 0.88 & 1.39 & 6.18 & & 148.1 & 13.29 & 11.9 \\
\hline & ISM & $1.2 \pm 0.05$ & $0.28 \pm 0.02$ & $0.10 \pm .01$ & $7.0 \pm 0.1$ & & & $15.3 \pm 0.1$ & $13.4 \pm 0.1$ \\
\hline \multirow[t]{3}{*}{3} & Inoculum & $0.25 \pm 0.03$ & $0.0 \pm 0.0$ & $0.0 \pm 0.0$ & $7.3 \pm 0.1$ & $10.0 \pm 1.8$ & & $13.8 \pm 0.7$ & $11.8 \pm 0.6$ \\
\hline & Feces & 3.82 & 1.15 & 0.80 & 6.3 & & 195.2 & 13.24 & 11.9 \\
\hline & ISM & $1.79 \pm 166.4$ & $0.25 \pm 135.5$ & $0.08 \pm 0.01$ & $7.0 \pm 0.2$ & $9.6 \pm 0.56$ & & $16.4 \pm 0.3$ & $14.3 \pm 0.3$ \\
\hline \multirow[t]{3}{*}{4} & Inoculum & $0.244 \pm 0.01$ & $0.01 \pm 0.01$ & $0.14 \pm 0.02$ & $7.6 \pm 0.0$ & & & $14.5 \pm 0.3$ & $12.4 \pm 0.3$ \\
\hline & Feces & 3.99 & 1.05 & 0.65 & 6.64 & & 173.5 & 13.22 & 11.8 \\
\hline & ISM & $1.16 \pm 0.08$ & $0.24 \pm 0.03$ & $0.12 \pm 0.11$ & $7.2 \pm 0.1$ & & & $17.0 \pm 0.6$ & $14.8 \pm 0.5$ \\
\hline \multirow[t]{3}{*}{5} & Inoculum & $\mathrm{NA}$ & NA & $\mathrm{NA}$ & $7.3 \pm 0.3$ & & NA & $15.2 \pm 0.3$ & $13.4 \pm 0.5$ \\
\hline & Feces & 4.31 & 1.10 & 0.78 & 5.1 & & 173.5 & 12.8 & 11.3 \\
\hline & ISM & $0.86 \pm 0.07$ & $0.23 \pm 0.03$ & $0.19 \pm 0.04$ & $7.0 \pm 0.1$ & & & $18.7 \pm 0.7$ & $16.5 \pm 0.7$ \\
\hline \multirow[t]{3}{*}{6} & Inoculum & $0.13 \pm 0.01$ & $10.02 \pm 0.0$ & $0.0 \pm 0.0$ & $7.5 \pm 0.5$ & & & $16.8 \pm 0.1$ & $14.6 \pm 0.1$ \\
\hline & Feces & 3.48 & 1.47 & 2.37 & 6.5 & & 183.2 & 12.8 & 11.3 \\
\hline & ISM & $0.56 \pm 0.13$ & $0.11 \pm 0.05$ & $0.11 \pm 0.03$ & $7.0 \pm 0.2$ & & & $19.3 \pm 0.5$ & $17.0 \pm 0.5$ \\
\hline \multirow[t]{3}{*}{7} & Inoculum & $0.18 \pm 0.04$ & $0.04 \pm 0.0$ & $0.06 \pm 0.01$ & $7.5 \pm 0.1$ & & & $17.6 \pm 0.3$ & $15.3 \pm 0.2$ \\
\hline & Feces & 3.69 & 1.00 & 0.72 & & & 183.2 & 12.8 & 11.3 \\
\hline & ISM & $0.35 \pm 0.13$ & $0.05 \pm 0.01$ & $0.06 \pm 0.01$ & $7.0 \pm 0.2$ & $9.4 \pm 0.42$ & & $20.7 \pm 0.4$ & $18.2 \pm 0.4$ \\
\hline \multirow[t]{3}{*}{8} & Inoculum & $0.18 \pm 0.03$ & $0.03 \pm 0.00$ & $0.21 \pm 0.03$ & $7.6 \pm 0.1$ & & & $18.7 \pm 0.3$ & $16.2 \pm 0.3$ \\
\hline & Feces & 1.54 & 0.46 & 0.26 & 6.95 & 5.5 & 184.2 & 12.53 & 11.2 \\
\hline & ISM & $0.93 \pm 0.06$ & $0.28 \pm 0.03$ & $0.29 \pm 0.03$ & $7.1 \pm 0.1$ & & & $20.7 \pm 1.3$ & $18.0 \pm 0.9$ \\
\hline \multirow[t]{3}{*}{9} & Inoculum & $0.13 \pm 0.02$ & $0.03 \pm 0.01$ & $0.18 \pm 0.02$ & $7.6 \pm 0.1$ & & & $19.5 \pm 0.1$ & $17.0 \pm 0.1$ \\
\hline & Feces & 1.54 & 0.46 & 0.26 & 6.95 & 5.5 & 184.2 & 12.53 & 11.2 \\
\hline & ISM & $0.59 \pm 0.08$ & $0.11 \pm 0.04$ & $0.23 \pm 0.04$ & $7.1 \pm 0.1$ & & & $21.5 \pm 0.4$ & $19.0 \pm 0.4$ \\
\hline \multirow[t]{3}{*}{10} & Inoculum & $0.18 \pm 0.04$ & $0.05 \pm 0.02$ & $0.11 \pm 0.03$ & $7.7 \pm 0.1$ & & & $20.0 \pm 0.2$ & $17.4 \pm 0.2$ \\
\hline & Feces & 5.0 & 1.34 & 2.22 & 6.17 & & 220.5 & 16.18 & 14.3 \\
\hline & ISM & $0.53 \pm 0.11$ & $0.05 \pm 0.01$ & $0.17 \pm 0.03$ & $7.2 \pm 0.1$ & & & $21.4 \pm 0.4$ & $18.7 \pm 0.3$ \\
\hline \multirow[t]{3}{*}{11} & Inoculum & $1.15 \pm 0.03$ & $0.03 \pm 0.02$ & $9.9 \pm 17.1$ & $7.7 \pm 0.1$ & $9.7 \pm 0.32$ & & $20.4 \pm 0.4$ & $17.6 \pm 0.4$ \\
\hline & Feces & 5.0 & 1.34 & 2.22 & 6.17 & & 220.5 & 16.18 & 14.3 \\
\hline & ISM & $0.23 \pm 0.04$ & $0.03 \pm 0.02$ & $0.0 \pm 0.0$ & $7.1 \pm 0.3$ & $9.6 \pm 0.32$ & & $22.0 \pm 0.7$ & $19.3 \pm 0.7$ \\
\hline $1-11$ & Wheat straw & - & - & - & - & - & 1097 & $89.0 \pm 0.0$ & $85 \pm 0.1$ \\
\hline
\end{tabular}

ISM inoculum-substrate mixture

to facilitate the analysis, fitted with FID, and equipped with a J\&W Scientific DB-FFAP high resolution column $(30 \mathrm{~m} \times 0.53 \mathrm{~mm} \times 1.00 \mu \mathrm{m}$; Chromatographic Specialties Inc., ON, Canada) (Massé et al. 2003). Helium, flowing at $9.5 \mathrm{~mL} \mathrm{~min}{ }^{-1}$, was employed as the carrier gas. The injector temperature was maintained at $200{ }^{\circ} \mathrm{C}$, while the detector temperature was set at $250{ }^{\circ} \mathrm{C}$.

\section{Fiber analysis}

The complex substrate (cow feces and wheat straw) were subjected to fiber analysis to determine their content of cellulose, hemicellulose, and lignin. Hemicellulose can be calculated as the difference between neutral detergent fiber (NDF) and acid detergent fiber (ADF), cellulose as the difference between acid detergent fiber and acid detergent lignin (ADL) (Bauer et al. 2009; Saady and Massé 2013).

\section{Results}

The percent of $\mathrm{H}_{2} \mathrm{~S}$ in the biogas was less than $0.06 \%$ in all samples of gas analyzed during the successive cycles. Different cow feces batches sourced from the same dairy 


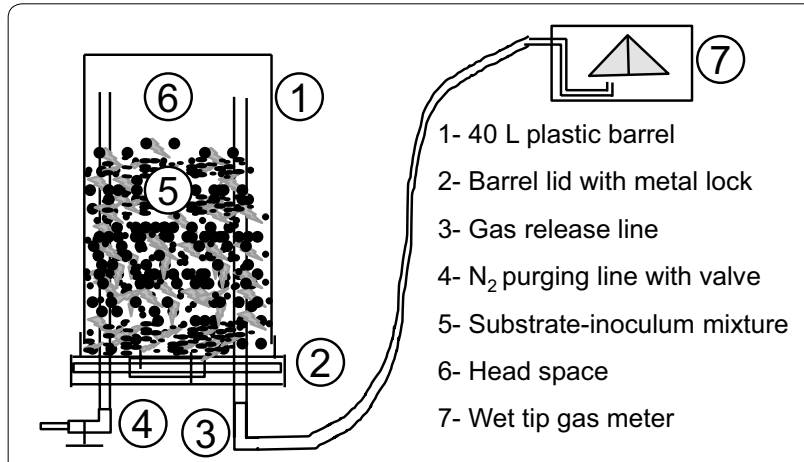

Fig. 1 Schematic diagram of the dry anaerobic digester

barn at DSRDC, Sherbrooke, QC, Canada were used during the 11 cycles as indicated in Table 2 . The overall average of the fiber components content (dry matter-based) for all cycles was $24.6 \pm 1.4 \%$ (cellulose), $21.2 \pm 3.7 \%$ (hemicellulose), and $12.2 \pm 1.6 \%$ (lignin). Wheat straw fibers were composed of cellulose (38.61\%), hemicellulose $(25.14 \%)$ and lignin $(7.3 \%)$; the same batch of wheat straw has been used during all cycles.

\section{Methane production}

The performance of psychrophilic anaerobic bioreactors has been evaluated in 11 successive cycles. Methane production profiles were expressed as average specific SMY of the triplicate bioreactors are shown in Fig. 2. The SMYs calculated during the successive cycles are given in Table 3. The SMY has been given per unit mass of VS and TCOD. The profiles of SMY (Fig. 2) showed stable and reproducible methane production with no lag-phases, inhibition, or discontinuation.
Based on the total VS fed (cow feces plus wheat straw), the average SMY calculated for the triplicate bioreactors ranged between $165.7 \pm 5.4$ and $213.9 \pm 13.6 \mathrm{NL}$ $\mathrm{CH}_{4} \mathrm{~kg}^{-1}$ VS during the 11 successive cycles operated at OLR of $3.0 \mathrm{~g}^{\mathrm{TCOD} \mathrm{kg}} \mathrm{k}^{-1}$ inoculum day ${ }^{-1}$ (equivalent to $2.2 \pm 0.1 \mathrm{~g} \mathrm{VS} \mathrm{kg}^{-1}$ inoculum day ${ }^{-1}$ ) and TCL of 21 days (Fig. 2; Table 4). The overall average SMY of the 11 successive cycles was $187.9 \pm 16.5 \mathrm{NL} \mathrm{CH}_{4} \mathrm{~kg}^{-1} \mathrm{VS}$ (139.9 $\left.\pm 13.1 \mathrm{NL} \mathrm{CH}_{4} \mathrm{~kg}^{-1} \mathrm{TCOD}\right)$.

The average specific $\mathrm{CH}_{4}$ production rate $\left(\mathrm{NL} \mathrm{CH}_{4}\right.$ $\mathrm{kg}^{-1} \mathrm{VS}$ day $^{-1}$ ) of the replicate bioreactors ranged between $7.9 \pm 0.3$ (cycle 8 ) and $10.2 \pm 0.6$ (cycle 3 ). The overall average of the specific $\mathrm{CH}_{4}$ production rate for the 11 successive cycles was $9.0 \pm 0.8 \mathrm{NL} \mathrm{CH}_{4} \mathrm{~kg}^{-1} \mathrm{VS}$ day $^{-1}$.

\section{Volatile fatty acids (VFAs) production}

Profiles of acetic, propionic, and butyric acids produced during the successive cycles of PDAD were similar but at different concentration levels. The acetate profile is shown in Fig. 3. Throughout the successive cycles, acetic acid concentration peaked immediately after feeding to levels between 1000 and $1500 \mathrm{mg} \mathrm{L}^{-1}$ but was consumed within a week in all replicate bioreactors and its concentrations were maintained within $150 \pm 50 \mathrm{mg} \mathrm{L}^{-1}$ indicating that methanogenesis reaction from acetate was not a rate limiting step after the first week. Similarly, propionic acid peaked to levels between 500 and $600 \mathrm{mg} \mathrm{L}^{-1}$ after feedings and was consumed within a week to levels close to the detection limits of the instrument $\left(25 \pm 10 \mathrm{mg} \mathrm{L}^{-1}\right)$.

The profile of propionic acid in the replicate bioreactors was similar to that of acetic acid. Butyric acid peaked

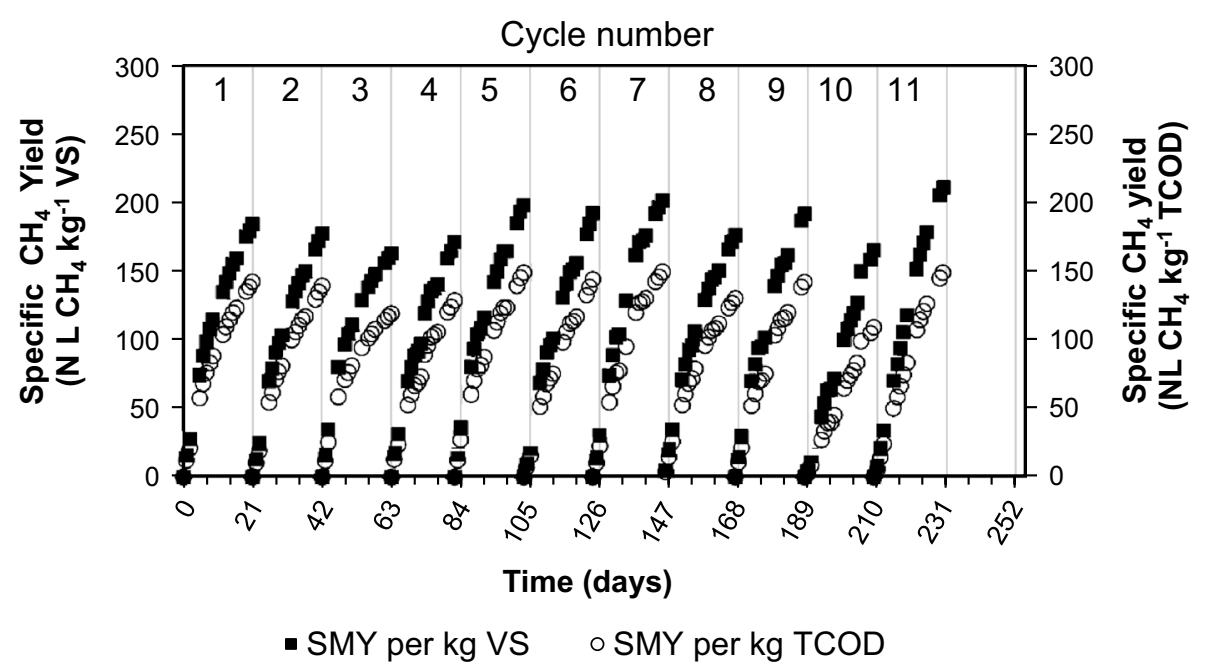

Fig. 2 Specific methane yield profiles for psychrophilic dry anaerobic digestion of cow feces and wheat straw (35 \% TS) 
Table 3 Rate and specific methane yield for the psychrophilic dry anaerobic digestion of cow feces and wheat straw (35\% TS)

\begin{tabular}{|c|c|c|c|c|c|c|}
\hline Cycle & $\begin{array}{l}\text { Cow feces } \\
\text { TCOD }\left(\mathbf{g ~ k g}^{-1}\right)\end{array}$ & $\begin{array}{l}\text { Cow feces } \\
\text { TCOD/VS }\end{array}$ & $\begin{array}{l}\text { Feed TCOD/ } \\
\text { VS ratio }\end{array}$ & $\begin{array}{l}\mathrm{SMY}\left(\mathrm{NL} \mathrm{CH}_{4}\right. \\
\left.\mathrm{kg}^{-1} \mathrm{VS}\right)\end{array}$ & $\begin{array}{l}\mathrm{SMY}\left(\mathrm{NL} \mathrm{CH}_{4}\right. \\
\left.\mathrm{kg}^{-1} \mathrm{TCOD}\right)\end{array}$ & $\begin{array}{l}\text { Rate of } \mathrm{CH}_{4} \\
\text { production }\left(\mathrm{NL} \mathrm{CH}_{4}\right. \\
\left.\mathrm{kg}^{-1} \mathrm{VS} \mathrm{day}^{-1}\right)\end{array}$ \\
\hline 1 & 147.6 & 1.3 & 1.3 & $184.6 \pm 14.4$ & $142.3 \pm 11.1$ & $8.8 \pm 0.7$ \\
\hline 2 & 148.0 & 1.2 & 1.3 & $177.7 \pm 24.4$ & $139.0 \pm 19.1$ & $8.5 \pm 1.2$ \\
\hline 3 & 195.2 & 1.6 & 1.4 & $213.9 \pm 13.6$ & $155.9 \pm 9.9$ & $10.2 \pm 0.6$ \\
\hline 4 & 173.9 & 1.5 & 1.3 & $173.4 \pm 17.8$ & $128.6 \pm 9.9$ & $8.3 \pm 0.9$ \\
\hline 5 & 173.9 & 1.5 & 1.3 & $198.2 \pm 20.6$ & $148.9 \pm 10.9$ & $9.4 \pm 1.0$ \\
\hline 6 & 173.9 & 1.5 & 1.3 & $200.9 \pm 9.9$ & $144.2 \pm 12.0$ & $9.6 \pm 0.5$ \\
\hline 7 & 184.2 & 1.6 & 1.4 & $186.3 \pm 28.6$ & $149.6 \pm 25.8$ & $8.9 \pm 1.4$ \\
\hline 8 & 184.2 & 1.6 & 1.4 & $165.7 \pm 5.4$ & $125.1 \pm 4.9$ & $7.9 \pm 0.3$ \\
\hline 9 & 184.2 & 1.6 & 1.4 & $191.3 \pm 5.6$ & $142.2 \pm 3.9$ & $9.1 \pm 0.3$ \\
\hline 10 & 220.5 & 1.5 & 1.4 & $165.4 \pm 9.8$ & $109.8 \pm 13.0$ & $7.9 \pm 0.5$ \\
\hline 11 & 220.5 & 1.5 & 1.4 & $209.1 \pm 21.4$ & $149.0 \pm 10.9$ & $10.0 \pm 1.0$ \\
\hline
\end{tabular}

The treatment cycle length in all cycles was 21 days

The numbers given are averages and standard deviations of triplicates bioreactors

The OLR was maintained at $3.0 \mathrm{~g} \mathrm{TCOD} \mathrm{kg}^{-1}$ inoculum day ${ }^{-1}$ equivalent to $\left(2.2 \pm 0.1 \mathrm{~g} \mathrm{VS} \mathrm{kg}^{-1}\right.$ inoculum day $\left.{ }^{-1}\right)$

The SMY in Table 3 is based on the quantity of VS fed (cow feces and wheat straw)

also to levels between 300 and $500 \mathrm{mg} \mathrm{L}^{-1}$ after feedings and was consumed within a week to levels close to the detection limits of the instrument $\left(25 \pm 10 \mathrm{mg} \mathrm{L}^{-1}\right)$. The concentrations of other volatile fatty acids (isobutyric-, iso-valeric-, and valeric-acid) were less than $50 \mathrm{mg} \mathrm{L}^{-1}$ immediately after feeding and less than $25 \mathrm{mg} \mathrm{L}^{-1}$ during the remaining time of the successive cycles.

\section{Solids profiles and removal}

The profiles of the TS and VS in the replicate bioreactors during the successive cycles were identical (data not shown). Starting from cycle 7 the variation in the inoculum TS between successive cycles stabilized below $5 \%$ (during cycle 10 and 11 it was 2.6 and $2.0 \%$, respectively). Similarly, starting from cycle 7 the variation in the inoculum VS between successive cycles stabilized below $5 \%$ (during cycle 10 and 11 it was 2.4 and $1.1 \%$, respectively). During the last three cycles $(9,10$, and 11$)$ the inoculum TS stabilized around $20.0 \pm 0.5 \%$ while the inoculum VS stabilized around $17.3 \pm 0.3 \%$. The reduction in the feedto-effluent TS ranged between 19.6 and $42.1 \%$ while the reduction of VS ranged from 17.2 to $38.3 \%$. The overall average reduction in the TS and VS were $31.7 \pm 6.7$ and $29.5 \pm 7.6 \%$, respectively.

\section{Discussion}

Due to the nature of substrate fed which contained lignocellulose components and the relatively short treatment cycle length (21 days) the cumulative SMY did not reach plateau. Therefore, residual substrate has been carried over from cycle to cycle.
Although the OLR (3.0 g TCOD kg ${ }^{-1}$ inoculum day ${ }^{-1}$ ), the feed total solids ( $35 \%$ ), and the TCL ( 21 days) have been maintained the same during the cycles 1-11, respectively, the SMY fluctuated from cycle to cycle likely due to the variable quality of the cow feces fed; the quality of the biodegradable organic materials in cow feces is a function of cow diet composition, as well as the quality of the inoculum. Notice that the yield achieved during the first cycle $\left(184.6 \pm 14.4 \mathrm{NL} \mathrm{CH}_{4} \mathrm{~kg}^{-1} \mathrm{VS}\right)$ was similar to the overall average SMY for the 11 successive cycles $\left(187.9 \pm 16.5 \mathrm{NL} \mathrm{CH}_{4} \mathrm{~kg}^{-1} \mathrm{VS}\right)$ which indicates a relatively fast start up likely because the inoculum was welladapted to the psychrophilic conditions and the high solids content (35\%) for long time.

Generally, the consistency of the performance of the replicate bioreactors indicates a rapid start-up, stable reproducible process during the 231 days of operation which could be attributed to the increase in the population of the microorganisms due to the increase in the fiber in the biomass.

The dry matter of wheat straw is composed of cellulose (38.61 \%), hemicellulose (25.14 \%) and lignin (7.3\%). Complete degradation of wheat straw during anaerobic digestion requires long retention time because its hydrolysis is a rate limiting step since it is in solid or particulate form (Myint and Nirmalakhandan 2006). However, the solid retention time (SRT) has been decoupled from the TCL by operating the bioreactors as sequential batch reactors with SRT of about 169 days. Notice that wheat straw formed $74.5 \pm 3.8 \%$ of the VS in feed, $78.2 \pm 3.5 \%$ of the feed fibers, $73.1 \pm 4.0 \%$ of the TS in 
Table 4 Comparative performance of dry anaerobic digestion of cow manure and wheat straw

\begin{tabular}{|c|c|c|c|c|c|c|c|}
\hline $\begin{array}{l}\text { Substrate and } \\
\text { inoculum }\end{array}$ & $\begin{array}{l}\text { Temperature } \\
\left({ }^{\circ} \mathrm{C}\right)\end{array}$ & TS (\%) & ISR & $\begin{array}{l}\text { OLR (g TCOD kg-1 } \\
\text { inoculum day }{ }^{-1} \text { ) }\end{array}$ & $\begin{array}{l}\text { Retention } \\
\text { time (days) }\end{array}$ & $\begin{array}{l}\mathrm{SMY}\left(\mathrm{NL} \mathrm{CH}_{4} \mathrm{~kg}^{-1}\right. \\
\text { VS) }\end{array}$ & References \\
\hline $\begin{array}{l}\text { Cow feces and wheat } \\
\text { straw }\end{array}$ & 20 & 35 & $4.1-4.5$ & 3.0 & 21 & $187.9 \pm 16.5$ & This study \\
\hline $\begin{array}{l}\text { Cow feces and wheat } \\
\text { straw }\end{array}$ & 20 & 27 & 3.0 & 3.0 & 21 & $182.9 \pm 16.9$ & $\begin{array}{l}\text { Massé and Saady } \\
\quad(2015 c)\end{array}$ \\
\hline $\begin{array}{l}\text { Cow feces and wheat } \\
\text { straw }\end{array}$ & 20 & 27 & 2.5 & 4.0 & 21 & $187.3 \pm 18.4$ & $\begin{array}{l}\text { Saady and Massé } \\
\text { (2015) }\end{array}$ \\
\hline $\begin{array}{l}\text { Cow feces and wheat } \\
\text { straw }\end{array}$ & 20 & 27 & 1.7 & 5.0 & 21 & $163.6 \pm 39.5$ & $\begin{array}{l}\text { Saady and Massé } \\
\text { (2015) }\end{array}$ \\
\hline $\begin{array}{l}\text { Cow feces and wheat } \\
\text { straw }\end{array}$ & 20 & 27 & 1.4 & 6.0 & 21 & $150.8 \pm 32.9$ & $\begin{array}{l}\text { Saady and Massé } \\
\text { (2015) }\end{array}$ \\
\hline $\begin{array}{l}\text { Cow feces and wheat } \\
\text { straw }\end{array}$ & 20 & 27 & 1.7 & 7.0 & 21 & $147.1 \pm 17.2$ & $\begin{array}{l}\text { Massé and Saady } \\
\text { (2015a) }\end{array}$ \\
\hline $\begin{array}{l}\text { Cow feces and wheat } \\
\text { straw }\end{array}$ & 20 & 27 & 1.4 & 8.0 & 21 & $143.2 \pm 11.7$ & $\begin{array}{l}\text { Massé and Saady } \\
\text { (2015a) }\end{array}$ \\
\hline CM:WWS (2:3 mass ratio) & 35 & 16 & 0.2 & $0.35^{\mathrm{a}}$ & 63 & 328 & Li et al. (2011a) \\
\hline \multirow{2}{*}{$\begin{array}{l}\text { Aerobically pre-treated } \\
\text { SM, agricultural } \\
\text { residues }\end{array}$} & 35 & 28 & $N R$ & $0.28^{\mathrm{b}}$ & 130 & 55 & \multirow[t]{2}{*}{ Di Maria et al. (2012) } \\
\hline & 35 & 28 & NR & $0.28^{\mathrm{b}}$ & 65 & 22 & \\
\hline DM and SG & 55 & 15 & 0.2 & $N R$ & 62 & $28^{c}$ & Ahn et al. (2010) \\
\hline \multirow{5}{*}{$\begin{array}{l}\text { Rice straw and corn stover } \\
\text { inoculated with }(1: 1) \\
\text { sewage sludge: pig } \\
\text { manure }\end{array}$} & & 15 & & NR & 156 & 346 & \multirow[t]{5}{*}{ Sun et al. (1987) } \\
\hline & & 20 & & NR & 156 & 339 & \\
\hline & $26-28$ & 25 & 0.2 & NR & 168 & 382 & \\
\hline & & 30 & & NR & 198 & 423 & \\
\hline & & 35 & & NR & 198 & 34 & \\
\hline $85 \%$ BM plus $15 \%$ GS & 35 & 28 & NR & 0.9 & 100 & $227^{c}$ & Schäfer et al. (2006) \\
\hline Beef manure plus straw & 32 & 18 & $N R$ & 3.2 & 28 & $181^{c}$ & Schäfer et al. (2006) \\
\hline $\begin{array}{l}\text { SM, turnip rape straw and } \\
\text { wheat straw }\end{array}$ & 35 & 16 & NR & NR & 120 & $122^{c}$ & Schäfer et al. (2006) \\
\hline DM, straw, and oat husk & 38 & 17 & NR & 3.4 & 22 & $160^{c}$ & Schäfer et al. (2006) \\
\hline DM, straw, and oat husk & 38 & 17 & NR & 4.1 & 22 & 84 & Schäfer et al. (2006) \\
\hline \multirow[t]{3}{*}{ Fresh HM and straw } & 37 & 20 & 0.2 & NR & 28 & 146 & \multirow[t]{3}{*}{ Kusch et al. (2008) } \\
\hline & 37 & 20 & 0.2 & NR & 42 & 175 & \\
\hline & 37 & 20 & 0.2 & NR & 72 & 208 & \\
\hline
\end{tabular}

$B M$ beef manure, $C M$ cow manure, DM dairy manure, GS grass silage, HM Horse manure, $P M$ poultry manure, $S G$ switchgrass, $S M$ swine manure, WWS wastewater sludge, $N R$ not reported

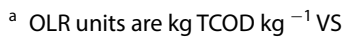

b OLR units are kg VS substrate $\mathrm{kg}^{-1}$ VS inoculum

c SMY units are $\mathrm{LCH}_{4} \mathrm{~kg}^{-1} \mathrm{VS}$

feed, $71.3 \pm 4.5 \%$ of the TCOD fed, and $29.3 \pm 2.2 \%$ of the mass of feed (data not shown).

The authors of this study have recently published on psychrophilic dry anaerobic digestion of cow feces and wheat straw (27\% TS in feed) at OLR 3.0-8.0 g TCOD kg ${ }^{-1}$ inoculum day ${ }^{-1}$ (Massé and Saady 2015a, b, c; Saady and Massé 2015). Nevertheless, data on performance of PDAD of cow feces and wheat straw is not available in the accessible literature; therefore, the results have been compared to the performance of mesophilic and thermophilic DAD of various substrates as well as to the data recently published by the authors on
PDAD of cow feces and wheat straw at feed TS of $27 \%$ (Table 4). Interestingly, the average SMY $(187.9 \pm 16.5$ $\mathrm{NL} \mathrm{CH}_{4} \mathrm{~kg}^{-1}$ VS) obtained from feed TS of $35 \%$ applied at OLR of $3.0 \mathrm{~g}^{\text {TCOD kg }}{ }^{-1}$ inoculum day ${ }^{-1}$ was statistically not different from the SMYs $(182.9 \pm 16.9$ and $187.3 \pm 18.4 \mathrm{NL} \mathrm{CH}_{4} \mathrm{~kg}^{-1}$ VS) obtained from feed TS $27 \%$ and OLR of 3.0 and $4.0 \mathrm{~g}$ TCOD kg-1 inoculum day $^{-1}$, respectively. The average yield of $187.9 \pm 16.5 \mathrm{NL}$ $\mathrm{CH}_{4} \mathrm{~kg}^{-1} \mathrm{VS}$ of cow feces and wheat straw (35\% TS at

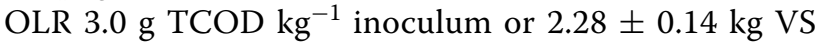
fed $\mathrm{kg}^{-1}$ inoculum day ${ }^{-1}$ ) obtained in this study after 21 days of psychrophilic $\left(20{ }^{\circ} \mathrm{C}\right)$ incubation during 


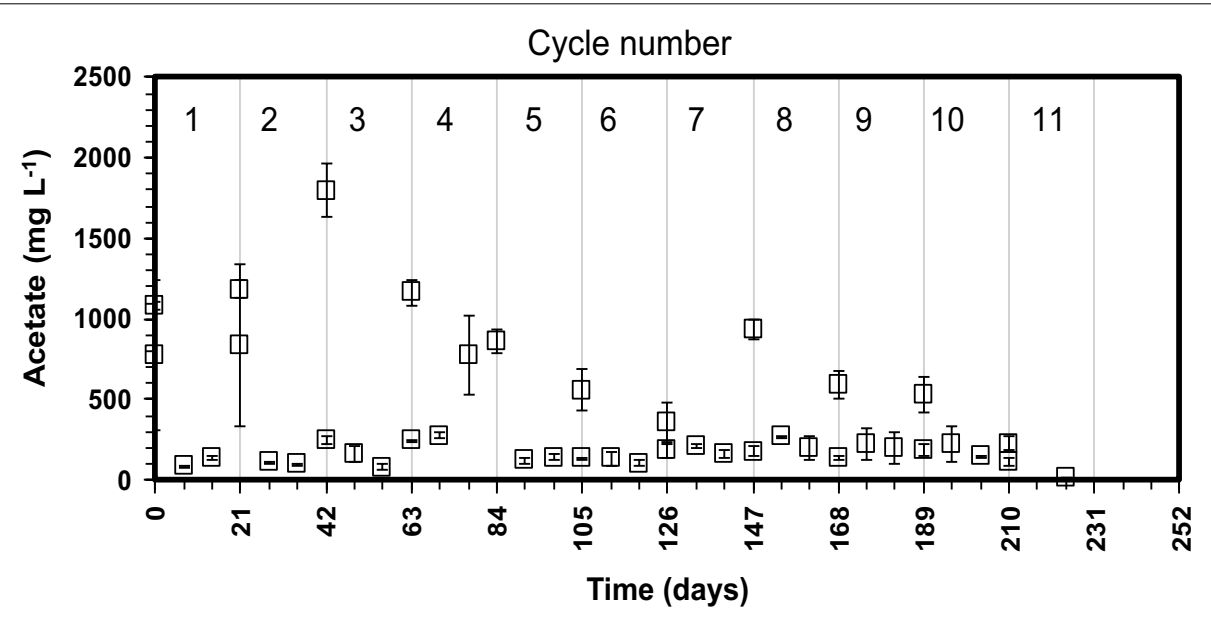

Fig. 3 Acetic acid profile for the cow feces and wheat straw psychrophilic dry anaerobic digestion at $35 \%$ total solids in feed

the 11 successive cycles is greater than the yield 160 $\mathrm{NL} \mathrm{CH}_{4} \mathrm{~kg}^{-1}$ VS of dairy manure, straw, and oat husk (TS $17 \%$ at OLR of $3.4 \mathrm{~g} \mathrm{VS} \mathrm{kg}^{-1}$ day $^{-1}$ ) reported by Schäfer et al. (2006) for Jarna biogas plant in Sweden which operates at $38{ }^{\circ} \mathrm{C}$ and retention time of 22 days. Notice that the data reported from Jarna plant is for a steady-state condition where the inoculum was adapted to the substrate and the operation condition for 3 years at the time of the study reported by Schäfer et al. (2006). The SMYs from cow feces and wheat straw at a TCL of 21 days in any of the PDAD eleven successive cycles (TS $35 \%$ ) obtained in this study were higher than $28 \mathrm{~L} \mathrm{CH}_{4}$ $\mathrm{kg}^{-1}$ VS of dairy manure and switch grass (15\% TS) obtained by Ahn et al. (2010) during 62 days of thermophilic $\left(55{ }^{\circ} \mathrm{C}\right)$ incubation. The difference between Ahn et al. (2010) and this study results demonstrate the importance of prolonged adaptation period and the importance of ISR. Ahn et al. (2010) used low ISR (0.2) and non-adapted inoculum in short time study while in this study the inoculum was adapted during around 36 months to stepwise increase in the feed's total solids (data not shown) and sufficient quantity of inoculum has been used (VS-based ISR ranged between 1.7 and 3.8). The average SMY $\left(188 \pm 17 \mathrm{NL} \mathrm{CH}_{4} \mathrm{~kg}^{-1}\right.$ VS) is similar to $181 \mathrm{~L} \mathrm{CH}_{4} \mathrm{~kg}^{-1} \mathrm{VS}$ of beef manure and straw (TS $18 \%$ and OLR of $3.2 \mathrm{~g} \mathrm{VS} \mathrm{kg}^{-1}$ day $^{-1}$ ) at $32{ }^{\circ} \mathrm{C}$ and retention time of 28 days reported previously (Schäfer et al. 2006) (Table 4). Compared to Schäfer et al. (2006) result, the current study demonstrated an increase of $94 \%$ in the feed total solids and reduction in the treatment cycle length by $25 \%$ while saving the energy consumed in heating the bioreactor (to increase the temperature from 20 to $37^{\circ} \mathrm{C}$ ); these improvements translate into 35 and $25 \%$ reduction in the required volume of the bioreactor, respectively, while at the same time cutting the reactor heating expenses by operating at psychrophilic condition. Notice that the high yields ( $>250 \mathrm{NL} \mathrm{CH}_{4} \mathrm{~kg}^{-1}$ VS fed) reported by $\mathrm{Li}$ et al. (2011a) was for mesophilic anaerobic digestion of cow manure and wastewater sludge (16\% TS) in 63 days of TCL. Similarly, the yield (339-423 $\mathrm{NL} \mathrm{CH}_{4} \mathrm{~kg}^{-1}$ total VS) reported by Sun et al. (1987) in Table 4 have been obtained for long retention times (156-198 days) and low OLR (0.35 kg TCOD kg-1 inoculum day $\left.{ }^{-1}\right)$ in mesophilic anaerobic digestion of rice straw and corn stover (TS 15-30\%). Interestingly, these researchers reported a very low SMY (34 $\mathrm{NL} \mathrm{CH}_{4} \mathrm{~kg}^{-1} \mathrm{VS}$ fed) for the same substrate and experimental conditions at TS $35 \%$. Achieving a stable dry anaerobic digestion of cow manure and wheat straw at psychrophilic condition and feed TS of $35 \%$ and OLR of OLR $3.0 \mathrm{~g} \mathrm{TCOD} \mathrm{kg}^{-1}$ inoculum or $2.28 \pm 0.14 \mathrm{~kg} \mathrm{VS}_{\text {fed }} \mathrm{kg}^{-1}$ inoculum day ${ }^{-1}$ over long-term start-up operation is a significant improvement given that $30 \%$ TS has been recently identified as a threshold above which methanogenesis was strongly inhibited for cardboard batch anaerobic digestion at $35^{\circ} \mathrm{C}$ (Abbassi-Guendouz et al. 2012).

\section{Inoculum-to-substrate ratio}

The ISR used in this study might be relatively high compared the ISR of 0.2 which has been used by some studies (Ahn et al. 2010; Kusch et al. 2008; Sun et al. 1987; $\mathrm{Li}$ et al. 2011a) (Table 4). However, the high total solids content of the substrate $(35 \%)$, psychrophilic $\left(20{ }^{\circ} \mathrm{C}\right)$ condition which decreases the rate of biological activity of microorganisms, and the recalcitrant nature of 


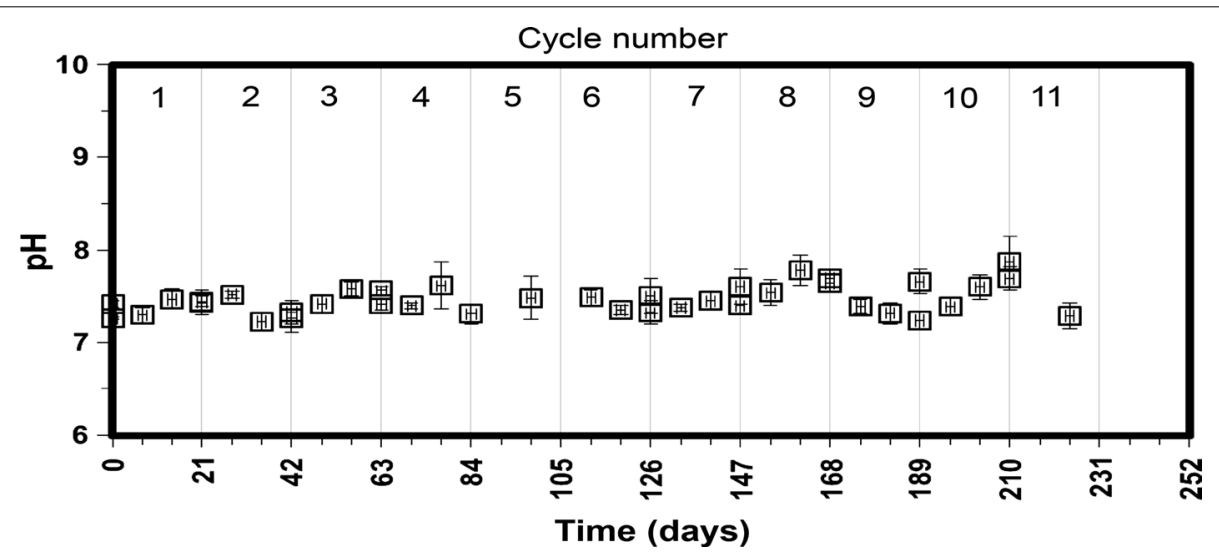

Fig. 4 pH profile for the cow feces and wheat straw psychrophilic dry anaerobic digestion at $35 \%$ total solids

lignocellulose components in wheat straw and cow feces all justify the relatively high ISR used in this work. It is worthwhile to notice that comparing 63, 62, and 168 days of cycle length to 21 days shows the novelty of the present study. Moreover, the SMY (28 $\left.\mathrm{L} \mathrm{CH}_{4} \mathrm{~kg}^{-1} \mathrm{VS}\right)$ for $15 \%$ TS dairy manure and Switchgrass digestion during 62 days of incubation at $55{ }^{\circ} \mathrm{C}$ was a sheer failure (Ahn et al. 2010); similarly 156-198 days (5.2-6.6 months of incubation) (Sun et al. 1987) is far from being practical and economic. The only promising result from the other studies cited in Table 4 would be that obtained SMY of $146 \mathrm{NL} \mathrm{CH}_{4} \mathrm{~kg}^{-1}$ total VS in 28 days at $37{ }^{\circ} \mathrm{C}$ from $20 \%$ TS fresh horse manure and straw (Kusch et al. 2008). Noting that this study increased the feed TS by $75 \%$ and decreased the temperature from 37 to $20^{\circ} \mathrm{C}$ justifies the relatively high ISR used.

Although the OLR used in this study $(2.2 \pm 0.1 \mathrm{~g}$ VS $\mathrm{kg}^{-1}$ inoculum day ${ }^{-1}$ ) is comparable that used in farm anaerobic digestion plants in Europe $\left(3.0 \mathrm{~g} \mathrm{TVS} \mathrm{\textrm {L } ^ { - 1 }}\right.$ reactor day ${ }^{-1}$ ) the TCL in this study is less by $50 \%$ (Bolzonella et al. 2011). The specific methane yields obtained in this study provide evidence that the start-up of PDAD of cow manure and straw is practically feasible at TS $35 \%$ within 147-210 days and is as efficient as mesophilic DAD given that a sufficient quantity of well-acclimatized inoculum is used.

The profiles of the VFAs concentration and the high level of methane production during the successive cycles indicate that acetogenic and methanogenic reactions proceeded fairly well. The relative stability of the $\mathrm{pH}$ profile around $7.2 \pm 0.6$ (Fig. 4) was due the sufficient alkalinity which ranged between $9.6 \pm 0.56$ and $9.4 \pm 0.42 \mathrm{~g} \mathrm{CaCO}_{3} \mathrm{~L}^{-1}$ for the inoculum-substrate mixture immediately after feeding. The alkalinity of the inoculum at the end of cycles ranged between $9.7 \pm 0.32$ and $\pm 11.8 \pm 0.65 \mathrm{~g} \mathrm{CaCO}_{3} \mathrm{~L}^{-1}$ (Table 2).

\section{Conclusions}

A successful start-up of psychrophilic $\left(20^{\circ} \mathrm{C}\right)$ dry anaerobic digestion of cow feces with wheat straw at $35 \%$ total solids in feed has been demonstrated within 147210 days (7-10 successive cycles of 21 TCL each). An average specific methane yield (SMY) of $188 \pm 17 \mathrm{NL}$ $\mathrm{CH}_{4} \mathrm{~kg}^{-1}$ VS fed $\left(140 \pm 13 \mathrm{NL} \mathrm{CH}_{4} \mathrm{~kg}^{-1}\right.$ TCOD fed $)$ has been achieved in 21 days treatment cycle length (TCL) at feed TS of $35 \%$ and OLR of $3.0 \mathrm{~g}_{\text {TCOD kg }}^{-1}$ inoculum day ${ }^{-1}$ in a laboratory scale sequencing batch reactor inoculated with psychrophilic anaerobic mixed culture. A maximum SMY of $214 \pm 14 \mathrm{NL} \mathrm{CH}_{4} \mathrm{~kg}^{-1}$ VS fed (156 $\pm 10 \mathrm{NL} \mathrm{CH}_{4} \mathrm{~kg}^{-1} \mathrm{COD}$ fed) with a maximum $\mathrm{CH}_{4}$ production rate of $10.2 \pm 0.6 \mathrm{NL} \mathrm{CH}_{4} \mathrm{~kg}^{-1} \mathrm{VS}$ day $^{-1}$ have been accomplished depending on the quality of cow feces fed. The process was stable with an overall average $30.9 \pm 6.6 \%$ reduction in the volatile solids. The measured volatile fatty acids concentrations indicated that hydrolysis was the reaction limiting step. The results indicate that dry anaerobic digestion of dairy cow manure and wheat straw at feed total solids of $35 \%$ and TCL of 21 in sequential batch reactor is feasible and as efficient as mesophilic operation.

\section{Authors' contributions}

DIM conceived the project and obtained the financial support; NMCS performed the experimental study; DIM and NMCS wrote the paper. Both authors read and approved the final manuscript.

\section{Acknowledgements}

This project has been financially supported by contributions of Agriculture and Agri-Food Canada. The authors also acknowledge the contribution of Mr. Denis Deslauriers, technician at Agriculture and Agri-Food Canada who was responsible for the laboratory analysis.

Compliance with ethical guidelines

Competing interests

The authors declare that they have no competing interests. 
Received: 4 May 2015 Accepted: 6 August 2015

Published online: 20 August 2015

\section{References}

Abbassi-Guendouz A, Brockmann D, Trably E, Dumas C, Delgenès J, Steyer J, Escudié R (2012) Total solids content drives high solid anaerobic digestion via mass transfer limitation. Bioresour Technol 111:55-61

Ahn HK, Smith MC, Kondrad SL, White JW (2010) Evaluation of biogas production potential by dry anaerobic digestion of switchgrass-animal manure mixtures. Appl Biochem Biotechnol 160(4):965-975

APHA (1992) Standard methods for the examination of water and wastewater, 18th edn. American Public Health Association, Washington, D.C.

Bauer A, Bösch P, Friedl A, Amon T (2009) Analysis of methane potentials of steam-exploded wheat straw and estimation of energy yields of combined ethanol and methane production. J Biotechnol 142(1):50-55

Bolzonella D, Cavinato C, Fatone F, Frison N, Pavan P, Cecchi F (2011) Anaerobic digestion of livestock effluents, energy crops, and agro-waste: renewable energy potential and nutrients management. Paper presented at the international symposium on anaerobic digestion of solid waste and energy crops (ADSW\&EC), Vienna

Challen Urbanic JM, VanOpstal B, Parker W (2011) Anaerobic digestion of the organic fraction of municipal solid waste (OFMSW) -full scale vs laboratory results. J Solid Waste Technol Manag 37(1):33-39. doi:10.5276/ jswtm.2011.33

Dhaked RK, Singh P, Singh L (2010) Biomethanation under psychrophilic conditions. Waste Manag 30(12):2490-2496. doi:10.1016/j.wasman.2010.07.015

Di Maria F, Gigliotti G, Sordi A, Micale C, Massaccesi L (2012) Start up of a preindustrial scale solid state anaerobic digestion cell for the co-treatment of animal and agricultural residues. In: ECOS 2012-the 25th international conference on efficiency, cost, optimization, simulation and environmental impact of energy systems, Perugia

El-Mashad HM, Zeeman G, Van Loon WKP, Bot GPA, Lettinga G (2004) Effect of temperature and temperature fluctuation on thermophilic anaerobic digestion of cattle manure. Bioresour Technol 95(2):191-201

Hofmann N, Beaulieu MS (2006) A geographical profile of manure production in Canada, 2001. Statistics Canada, Agriculture Division. Catalogue No. 21-601-MIE

Kashyap DR, Dadhich KS, Sharma SK (2003) Biomethanation under psychrophilic conditions: a review. Bioresour Technol 87(2):147-153. doi:10.1016/ S0960-8524(02)00205-5

Kusch S, Oechsner H, Jungbluth T (2008) Biogas production with horse dung in solid-phase digestion systems. Bioresour Technol 99(5):1280-1292

Lettinga G, Rebac S, Zeeman G (2001) Challenge of psychrophilic anaerobic wastewater treatment. Trends Biotechnol 19(9):363-370. doi:10.1016/ s0167-7799(01)01701-2

Li J, Jha AK, He J, Ban Q, Chang S, Wang P (2011a) Assessment of the effects of dry anaerobic codigestion of cow dung with waste water sludge on biogas yield and biodegradability. Int J Phys Sci 6(15):3679-3688

Li Y, Park SY, Zhu J (2011 b) Solid-state anaerobic digestion for methane production from organic waste. Renew Sustain Energy Rev 15(1):821-826

Luning L, Van Zundert EHM, Brinkmann AJF (2003) Comparison of dry and wet digestion for solid waste. Water Sci Technol 48:15-20

Massé DI, Patni NK, Droste RL, Kennedy KJ (1996) Operation strategies for psychrophilic anaerobic digestion of swine manure slurry in sequencing batch reactors. Can J Civ Eng 23(6):1285-1294

Massé DI, Droste RL, Kennedy KJ, Patni NK, Munroe JA (1997) Potential for the psychrophilic anaerobic treatment of swine manure using a sequencing batch reactor. Can Agric Eng 39(1):25-33
Massé DI, Masse L, Croteau F (2003) The effect of temperature fluctuations on psychrophilic anaerobic sequencing batch reactors treating swine manure. Bioresour Technol 89(1):57-62. doi:10.1016/ S0960-8524(03)00009-9

Massé DI, Croteau F, Masse L (2007) The fate of crop nutrients during digestion of swine manure in psychrophilic anaerobic sequencing batch reactors. Bioresour Technol 98(15):2819-2823

Massé DI, Masse L, Xia Y, Gilbert Y (2010) Potential of low-temperature anaerobic digestion to address current environmental concerns on swine production. J Anim Sci 88(13 Suppl):E112-E120

Massé DI, Saady NMC (2015a) Dry anaerobic digestion of high solids content dairy manure at high organic loading rates in psychrophilic sequence batch reactor. Appl Microbiol Biotechnol 99(10):4521-4529

Massé DI, Saady NMC (2015b) Psychrophilic dry anaerobic digestion of dairy cow feces: long-term operation. Waste Manag 36:86-92. doi:10.1016/j. wasman.2014.10.032

Massé DI, Saady NMC (2015c) Psychrophilic dry anaerobic digestion of high solids content dairy manure: long-term operation. Biol Eng Trans ASABE 7(3):99-112

Motte JC, Escudié R, Bernet N, Delgenes JP, Steyer JP, Dumas C (2013) Dynamic effect of total solid content, low substrate/inoculum ratio and particle size on solid-state anaerobic digestion. Bioresour Technol 144:141-148. doi:10.1016/j.biortech.2013.06.057

Myint M, Nirmalakhandan N (2006) Evaluation of first-order, second-order, and surface-limiting reactions in anaerobic hydrolysis of cattle manure. Environ Eng Sci 23(6):970-980. doi:10.1089/ees.2006.23.970

Ramasamy EV, Abbasi SA (2000) High-solids anaerobic digestion for the recovery of energy from municipal solid waste (MSW). Environ Technol 21(3):345-349

Saady NMC, Massé DI (2013) Psychrophilic anaerobic digestion of lignocellulosic biomass: a characterization study. Bioresour Technol 142:663-671. doi:10.1016/j.biortech.2013.05.089

Saady NMC, Massé DI (2015) Impact of organic loading rate on the performance of psychrophilic dry anaerobic digestion of dairy manure and wheat straw: long-term operation. Bioresour Technol 182:50-57. doi:10.1016/j.biortech.2015.01.065

Schäfer W, Lehto M, Teye F (2006) Dry anaerobic digestion of organic residues on-farm - a feasibility study. Agrifood Research Reports 77. MTT Agrifood Research Finland. http://www.mtt.fi/met/pdf/met77.pdf

Sun GC, Wu YZ, Sha SJ, Liu KX (1987) Dry digestion of crop wastes: studies on dry anaerobic digestion with agricultural wastes. Biol Wastes 20(4):291-302

Wen Z, Liao W, Chen S (2004) Hydrolysis of animal manure lignocellulosics for reducing sugar production. Bioresour Technol 91(1):31-39. doi:10.1016/ S0960-8524(03)00166-4

\section{Submit your manuscript to a SpringerOpen ${ }^{\circ}$ journal and benefit from:}

- Convenient online submission

- Rigorous peer review

- Immediate publication on acceptance

- Open access: articles freely available online

- High visibility within the field

- Retaining the copyright to your article

Submit your next manuscript at $\boldsymbol{~ s p r i n g e r o p e n . c o m ~}$ 